\title{
Induction of the phoE promoter upon invasion of Salmonella typhimurium into eukaryotic cells
}

\author{
Riny Janssen, ${ }^{1}$ Georges M. G. M. Verjans, ${ }^{2}$ Johannes G. Kusters ${ }^{3}$ and \\ Jan Tommassen ${ }^{1 *}$ \\ 'Department of Molecular Cell Biology and Institute of Biomembranes, Utrecht University, \\ Padualaan 8, $3584 \mathrm{CH}$ Utrecht, ${ }^{2}$ Department of Virology, Eramus University Rotterdam, \\ Dr. Molenwaterplein 50, 3015 GE Rotterdam and ${ }^{3}$ Department of Medical Microbiology, \\ School of Medicine, Vrije Universiteit, van der Boechorststraat 7, 1081 BT Amsterdam, \\ The Netherlands
}

(Received April 18, 1995; accepted in revised form August 7, 1995)

Janssen, $\mathbf{R}$ (Department of Molecular Cell Biology and Institute of Biomembranes, Utrecht University, Padualaan 8, 3584 CH Utrecht, The Netherlands), G. M. G. M. Verjans, J. G. Kusters and J. Tommassen. Induction of the phoE promoter upon invasion of Salmonella typhimurium into eukaryotic cells. Microbial Pathogenesis 1995; 19: 193-201.

Live attenuated Salmonella typhimurium strains expressing foreign antigens can be used for vaccination purposes. Due to deleterious effects of constitutive, high-level expression of the heterologous antigens, there is often strong selection pressure against plasmids encoding these antigens, resulting in rapid segregation in vivo. In vivo-inducible promoters may be a good alternative for constitutive promoters. The outer membrane protein PhoE of Escherichia coli is being used as a carrier for foreign antigenic determinants. Here we studied whether its expression from a plasmid is induced in S. typhimurium upon invasion of eukaryotic cells. This appeared to be the case. Furthermore, a $S$. typhimurium phoE mutant was constructed and the effects of the mutation on invasion, intracellular survival and virulence were studied. Survival in HEp-2 cells or in the macrophage-like cell line J744 was not, or only slightly, affected. Furthermore, the mutant appeared to be as virulent for mice as the wild-type strain.

(C) 1995 Academic Press Limited

Key words: PhoE; Salmonella typhimurium; in vivo inducible promoter; intracellular survival; virulence.

\section{Introduction}

In order to gain insight in the factors that determine bacterial virulence, a lot of effort has been put into the identification of genes that are expressed after invasion into eukaryotic cells. ${ }^{1,2}$ Furthermore, it has been suggested that in vivo inducible genes may contribute to virulence. ${ }^{3}$ Such genes have been identified using in vivo expression technology ${ }^{1}$ or transposon mutagenesis. ${ }^{2}$

It is anticipated that inside eukaryotic cells inorganic phosphate concentrations are very low since phosphate is usually bound in organic compounds. Bacteria like Escherichia coli and Salmonella typhimurium respond fiercely to phosphate starvation by the induction of the pho regulon (reviewed in ${ }^{4} \%$. One of these genes is the

\footnotetext{
* Author to whom correspondence should be addressed: J. Tommassen, Department of Molecular Cell Biology, Utrecht University, Padualaan 8, $3584 \mathrm{CH}$ Utrecht, The Netherlands.
} 
gene encoding the PhoE protein, ${ }^{5}$ which is pore-forming outer membrane protein. ${ }^{6}$ In the present study, we investigated whether the phoE promoter is induced after invasion, and whether PhoE expression is important for intracellular survival and for the pathogenesis of $S$. typhimurium. These studies are particularly interesting since we are also employing PhoE as a carrier for foreign antigenic determinants (reviewed in ${ }^{7}$ ). The major objective of these studies is the development of live oral vaccines. For this purpose high level and inducible expression of chimeric proteins by recombinant bacteria upon invasion of eukaryotic cells may be advantageous. When live bacteria that express foreign antigens or antigenic determinants are used for vaccination, features like antigen breakdown by the heterologous host and genetic instability of the recombinant strains, may occur. By using an expression system that is induced upon invasion, such problems may be circumvented.

\section{Results}

\section{phoE promoter activity after invasion}

To study whether the phoE promoter is induced upon invasion of $S$. typhimurium in eukaryotic cells, the virulent strain SL1344 was transformed either with plasmid pJP29, encoding E. coli PhoE, or with the vector pACYC184. Recombinant bacteria were used to infect HEp-2 cells and, after invasion, they were labelled with ${ }^{35} \mathrm{~S}$ methionine. For efficient incorporation of ${ }^{35} \mathrm{~S}$-methionine into bacterial proteins, protein synthesis of the host cells was inhibited with cycloheximide. ${ }^{8}$ After labelling, intracellular and extracellular bacteria were isolated and immunoprecipitations were performed using an antibody specific for $E$. coli PhoE trimers. Samples were analysed by SDS-PAGE and autoradiography. Bacteria grown extracellularly did not express PhoE (Fig. 1, lanes 2 and 4). As expected, also intracellular bacteria containing the

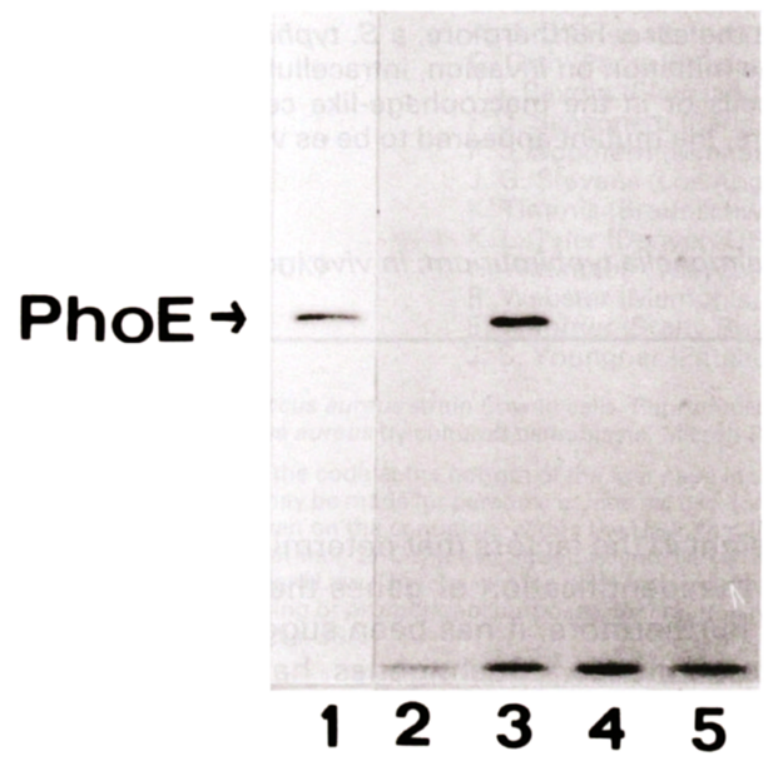

Fig. 1. Autoradiogram of an SDS-PAGE gel on which the immunoprecipitated E. coli PhoE was analysed which is expressed after invasion of recombinant $S$. typhimurium in HEp-2 cells. As a control, $E$. coli strain CE1224 containing plasmid pJP29 was grown in low phosphate conditions, labelled for $1 \mathrm{~h}$ with ${ }^{35} \mathrm{~S}$ methionine and radiolabelled PhoE was immunoprecipitated (lane 1). S. typhimurium strain SL1344 containing pJP29, encoding witd-type PhoE (lanes 2 and 3) or vector pACYC184 (lane 4 and 5) were used to invade HEp-2 cells. Intracellularly (lanes 3 and 5) and extracellularly (lanes 2 and 4) grown bacteria were labelled with ${ }^{35} \mathrm{~S}$-methionine and PhoE was immunoprecipitated as described in Materials and methods. 
vector plasmid pACYC184 did not express E. coli PhoE (Fig. 1, lane 5). In contrast, intracellular bacteria containing plasmid pJP29 did express $E$. coliPhoE after invasion (Fig. 1, lane 3). Similar results were obtained after invasion of Epstein Bar virustransformed B-cells (data not shown). To exclude a possible effect of cycloheximide on intracellular PhoE expression, similar experiments were performed in the absence of this drug. Also in these experiments, PhoE was expressed after invasion. However, as expected, labelling was less efficient (data not shown). In conclusion, the $E$. coli phoE promoter is active in the bacteria upon invasion of eukaryotic cells and this is consistent with the idea that there is inorganic phosphate limitation inside these cells.

\section{Construction of an S. typhimurium phoE mutant strain}

Both in E. coli ${ }^{5}$ and in $S$. typhimurium ${ }^{9}$ PhoE is expressed under phosphate starving conditions and the two promoters are very similar. ${ }^{10}$ Since the $E$. coli phoE promoter is active after invasion of pJP29-containing S. typhimurium into eukaryotic cells, the $S$. typhimurium phoE promoter is most probably also induced. Therefore, a possible role for PhoE in virulence was considered. To study whether expression of PhoE after invasion is of importance for the intracellular survival of $S$. typhimurium, the chromosomal phoE gene of strain SL1344 was inactivated by gene replacement as described in Materials and methods. Correct gene replacement was verified by Southern blotting (results not shown). A recombinant that showed the correct DNA hybridization pattern on a Southern blot was designated CE1432 and was grown in phosphate-starving conditions. Protein patterns of peptidoglycan-associated proteins were analysed by SDS-PAGE. In contrast to the parental strain (Fig. 2A, lane 3), the phoE mutant did not express PhoE when grown under phosphate limitation (Fig. $2 A$, lane 5). This result was verified by Western immunoblotting, using a monoclonal antibody that was raised against the denatured form of E. coli PhoE and that crossreacts with S. typhimurium PhoE (Fig. 2, panel B).

\section{Phenotype of the phoE mutant}

To establish possible deleterious effects of the phoE mutation on growth in laboratory conditions, wild-type strain SL1344 and the phoE mutant CE1432 were grown on LBmedium, on phosphate limiting medium and on a synthetic medium, to which 0.25 mM ATP was added as the sole phosphate source. When the growth curves were
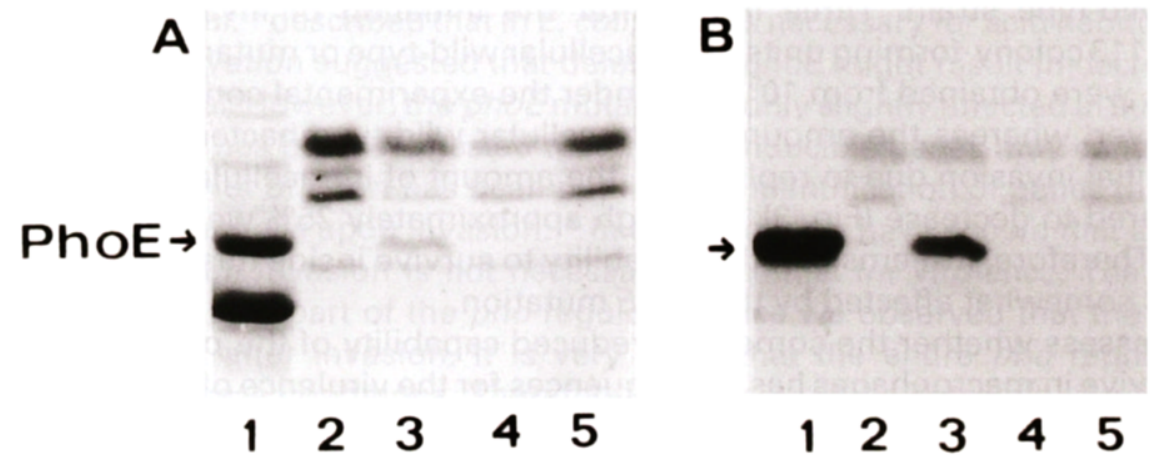

Fig. 2. SDS-PAGE gel (panel A) and Western immunoblot (panel B) of peptidoglycan-associated proteins of S. typhimurium strains SL1344 and its phoE mutant derivative CE 1432, grown on high phosphate- (lanes 2 and 4 ) or on low phosphate- (lanes 3 and 5) media. As a control, cell envelopes were isolated of $E$. coli strain CE1224 containing plasmid pJP29, encoding E. coli PhoE, which was grown in low phosphate medium (lane 1). The two protein bands that cross-react in the blot with the monoclonal antibody used are the structurally related $\mathrm{OmpF}$ and $\mathrm{OmpC}$ proteins. 


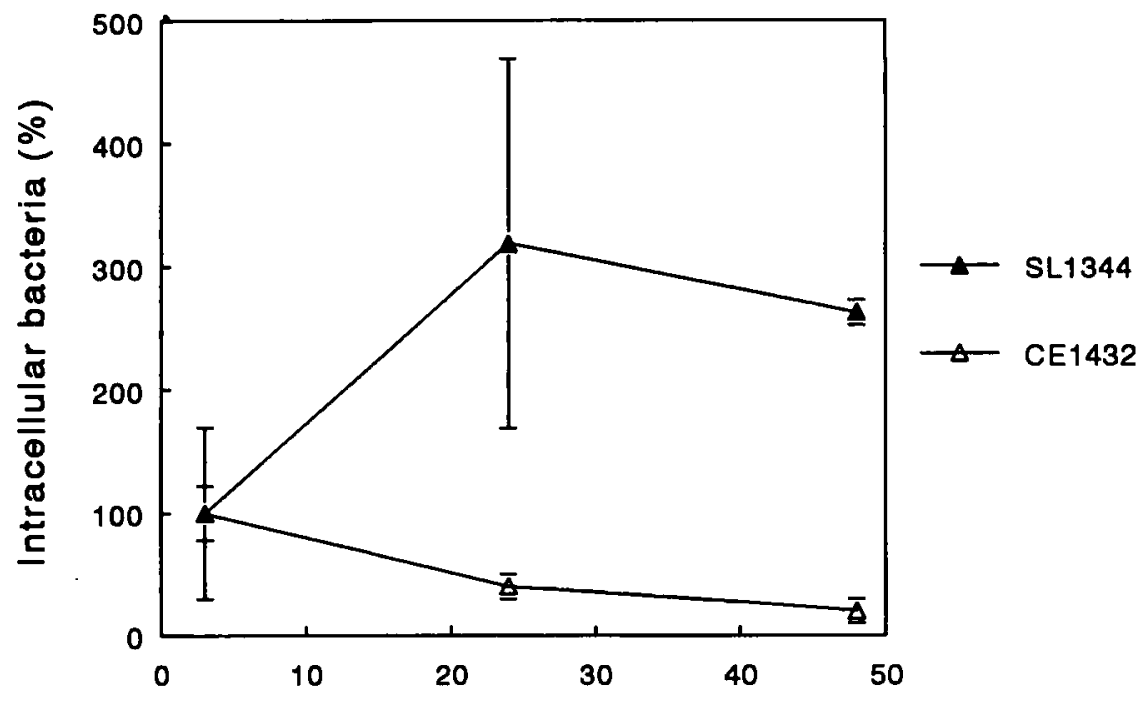

Time after invasion (hours)

Fig. 3. Survival of SL1344 and CE1432 in macrophage-like cell line J744. Intracellular bacteria were isolated at different time-points after invasion. The amount of intracellular bacteria, $\mathbf{3} \mathbf{h}$ after initiation of invasion was taken as $100 \%$. For the wild-type strain and the phoE mutant, this corresponded to $70 \pm 43$ and $500 \pm 113$ colony forming units, respectively. The mean value of duplicate samples for time point $3 \mathrm{~h}$ is given and of quadruplicate samples for time-points 24 and $48 \mathrm{~h}$.

followed by optical density measurements, no differences between the two strains were seen on either of these media (data not shown). Apparently, like in E. coli," PhoE expression is not essential for growth in phosphate-starving conditions.

To investigate whether PhoE expression is necessary for intracellular survival, an invasion and replication assay was performed in HEp-2 cells. It appeared that the intracellular survival of the PhoE mutant was not affected (data not shown). S. typhimurium is known to invade the gut via M-cells and is subsequently thought to enter and survive inside macrophages. ${ }^{2,12}$ Therefore, survival of the wild-type and the phoE mutant strain was also studied in the mouse macrophage cell line J744. The initial invasion of the mutant appeared to be more efficient than that of the wild-type strain. Three hours after the initiation of invasion, $70 \pm 43$ and $500 \pm 113$ colony-forming units of intracellular wild-type or mutant bacteria, respectively, were obtained from $10^{5}$ cells under the experimental conditions employed. However, whereas the amount of intracellular wild-type bacteria increased after the initial invasion due to replication, the amount of intracellular mutant bacteria appeared to decrease (Fig. 3), although approximately $25 \%$ were still viable after $48 \mathrm{~h}$. Therefore, it seems that the capability to survive inside this macrophage cellline is somewhat affected by the phoE mutation.

To assess whether the somewhat reduced capability of the phoE mutant strain to survive in macrophages has consequences for the virulence of the strain, groups of three mice were infected with either the wild-type or the phoE mutant strain. Two different doses $\left(5 \times 10^{6}\right.$ and $\left.5 \times 10^{7}\right)$ of the bacteria were administered intragastrically. As a control, a group of six mice received $10^{9}$ bacteria of strain SL3261, an aroA derivative of SL1344. There was no difference in virulence between the wild-type strain and the phoE mutant strain (Table 1). Mice died between 5 and 10 days after infection. In contrast, mice that were infected with the well-defined 
Table 1 Infection of mice with SL1344 and its phoE derivative CE $1432^{\circ}$

\begin{tabular}{lcc}
\hline Strain & Number of bacteria & Death rate \\
\hline SL1344 & $5 \times 10^{6}$ & $2 / 3$ \\
SL1344 & $5 \times 10^{7}$ & $3 / 3$ \\
CE1432 (phoE) & $5 \times 10^{6}$ & $3 / 3$ \\
CE1432 (phoE) & $5 \times 10^{7}$ & $3 / 3$ \\
SL3261 (aroA) & $10^{9}$ & $0 / 6$ \\
\hline
\end{tabular}

\footnotetext{
-Groups of three 8-week-old female Balb/c mice each were immunized orally with a suspension of bacteria in PBS. Mice were followed for 3 weeks. Mice died between 5 and 10 days after immunization.
}

attenuated strain SL3261 all survived the infection with $10^{\circ}$ bacteria. Hence, PhoE expression does not seem to be essential for virulence of SL1344.

\section{Discussion and conclusions}

The phoE promoter is normally induced when bacteria are grown in phosphatestarving conditions, and low inorganic phosphate concentration is the actual trigger for its activation. In the present study, we show that the $E$. coli phoE promoter is induced when $S$. typhimurium invades eukaryotic cells, indicating that the phoE promoter is an in vivo-inducible promoter. Therefore, it can also be concluded that there is phosphate limitation in the phagocytic compartment in eukaryotic cells, where $S$. typhimurium resides after invasion. ${ }^{12}$

Similar to in E. coli, deletion of the phoE gene in $S$. typhimurium did not result in less efficient growth in low phosphate conditions, indicating that PhoE expression is not essential for growth. Probably, other pore-forming proteins can compensate for the loss of PhoE function. Of course, it remains very well possible that the phoE mutant strain is less competitive when grown together with the wild-type strain on specific phosphate sources. Also for survival inside eukaryotic cells, PhoE expression is not essential although somewhat less efficient growth inside mouse macrophages (but not in HEp-2 cells) was observed for the mutant. However, deletion of the phoE gene did not result in attenuation of SL1344, indicating that PhoE is not a virulence factor. Rowbury et al. ${ }^{13}$ described that in $E$. coli, phoE is necessary for acid habituation in vitro. This observation suggested that deletion of phoE might result in decreased intracellular survival. However, the phoE mutant was only slightly affected in survival in macrophages. It has been suggested that in vivo inducible genes may contribute to virulence ${ }^{3}$ and a lot of effort has been put into the identification of genes that are expressed by Salmonella upon invasion. ${ }^{1,2}$ In this study, we have shown that a gene that is induced upon invasion is not necessarily essential for virulence. The phoE gene is expressed as a part of the pho regulon. ${ }^{5}$ Since we observed that the phoE gene is expressed after invasion, it is very likely that the entire pho regulon is expressed under these conditions. Therefore, it remains to be determined whether the products of other pho genes are important for virulence, e.g. by inactivation of the $p h o B$ gene, which encodes the transcriptional activator of the regulon.

Attenuated Salmonella strains are good candidates for the delivery of foreign antigens to the immune system. ${ }^{14-16}$ High-level expression of foreign or chimeric proteins can easily be accomplished in vitro. However, when recombinant bacteria are used for vaccination studies in vivo, high-level expression of foreign antigens 
can result in rapid plasmid segregation. Different approaches have been used to obtain stable expression of foreign antigens in vivo. For instance, Nakayama et al. ${ }^{17}$ and Curtiss et al. ${ }^{18}$ described a system to prevent plasmid segregation by inclusion of a gene on the plasmid that is essential for survival inside eukaryotic cells. This approach resulted in stable expression of the foreign antigens. However, when such foreign antigens are expressed constitutively, there is always the possibility that, due to deleterious effects of the expressed foreign antigen, mutations will occur that decrease the expression level. On the other hand, when the relevant gene is integrated in the chromosome, expression levels can drop so drastically due to the presence of only one single copy of the gene, that adequate immune responses are not anticipated. ${ }^{19,20}$ Tijhaar et al. ${ }^{21}$ described an invertible promoter segment that allows stable expression of foreign antigens in Salmonella. Such an invertible promoter segment can either be present in the wrong orientation or it can invert and drive expression of the gene under its control, resulting in expression of the foreign antigen in part of the population. Consequently, there will be no selection against the presence of the plasmid in that part of the population that does not express the foreign antigen. Theoretically, this would imply that even lethal expression levels would not lead to plasmid segregation in the total population. In this system, however, there may be selection against the situation in which the promoter drives expression of the foreign antigen. Therefore, the use of in vivo-inducible promoters instead of constitutive promoters, seems to be a good alternative.

The nirB promoter, which is induced in anaerobic conditions, has been shown to be suitable to obtain stable expression of foreign antigens in Salmonella. ${ }^{22}$ From the data presented here, it is feasible that stable expression of foreign antigens can be obtained in vivo, using the phoE promoter. Moreover, by genetic manipulation short amino acid sequences can be inserted in outer membrane protein PhoE, ${ }^{7}$ which can be expressed at high levels in $S$. typhimurium. ${ }^{23}$ This approach circumvents the problem of proteolytic antigen degradation, which often occurs when complete foreign antigens are expressed in bacteria. All these observations indicate that attenuated Salmonella strains expressing chimeric PhoE proteins are ideal candidates for the delivery of foreign antigenic determinants to the immune system.

\section{Materials and methods}

Bacterial strains, plasmids and growth conditions. The virulent $S$. typhimurium strain $\mathrm{SL} 1344^{24}$ and its aroA derivative SL3261 24 were kindly provided by B. A. D. Stocker (Department of Medical Microbiology, Stanford University, CA, U.S.A.). E. coli strain CE $1224^{25}$ does not produce pore proteins due to mutations in the phoE and ompR genes. Plasmids pJP29 $29^{26}$ and $\mathrm{pST}^{10}$, encode the E. coli and S. typhimurium PhoE, respectively. pACYC184 ${ }^{27}$ is a cloning vector and was also used for the isolation of the DNA fragment encoding a tetracycline resistance gene. Bacteria were grown at $37^{\circ} \mathrm{C}$ under aeration in Luria-Bertani medium, in phosphate-limiting medium ${ }^{28}$ or in a synthetic medium in which the phosphate concentration can be varied. ${ }^{5}$ When necessary tetracycline $(20 \mu \mathrm{g} / \mathrm{ml})$ or chloramphenicol $(25 \mu \mathrm{g} / \mathrm{ml})$ was added.

Cell cultures. All tissue culture reagents were obtained from GIBCO laboratories (Grand Island, NY, U.S.A.). Cells were grown in RPMI- 1640 or in DMEM, supplemented with $10 \%$ heatinactivated fetal calf serum, penicillin $(100 \mathrm{lU} / \mathrm{ml})$ and streptomycin $(100 \mu \mathrm{g} / \mathrm{ml})$ at $37^{\circ} \mathrm{C}$ in a $\mathrm{CO}_{2}$-incubator. The human larynx epithelial cell line HEp-2 (ATCC CCL 23) was obtained from the American Type Culture collection (Rockville, MD, U.S.A.). The Epstein Bar virus-transformed B-cell line JY has been described. ${ }^{29} \mathrm{~J} 774$ cells, a continuous macrophage-like cell line derived from a reticulum cell sarcoma, has been described by Ralph et al. ${ }^{30}$ For invasion assays, $2 \times 10^{5} \mathrm{HEp}-2$ cells were seeded in 6 -well dishes and incubated to semiconfluent 
monolayers (approximately $5 \times 10^{5}$ cells/well). Prior to the bacterial invasion assay, the cell lines were incubated overnight in culture medium without antibiotics.

Invasion and intracellular replication assay. An invasion assay was performed as described previously. ${ }^{31}$ Briefly, cells were infected with suspensions of logarithmically growing bacteria, at a nominal multiplicity of infection (MOl) of 10. Adhesion and subsequent invasion of bacteria was allowed to take place for $30 \mathrm{~min}$ at $37^{\circ} \mathrm{C}$. Extracellular bacteria were killed by incubation in RPMI-1640 supplemented with $10 \%$ fetal calf serum and $200 \mu \mathrm{g} / \mathrm{ml}$ gentamycin for $1 \mathrm{~h}$ at $37^{\circ} \mathrm{C}$ in a $\mathrm{CO}_{2}$ incubator. Celis were maintained in RPMI- 1640 supplemented with $10 \%$ fetal calf serum and $20 \mu \mathrm{g} / \mathrm{ml}$ gentamycin to prevent reinfection. At various time points after invasion, cells were lysed by incubation with PBS containing $1 \%(\mathrm{w} / \mathrm{v})$ saponin $(1 \mathrm{ml} / \mathrm{sample})$ for $5 \mathrm{~min}$ at room temperature to release intracellular bacteria. To determine the number of intracellular bacteria, suspensions were plated on LB-plates. To monitor intracellular bacterial protein synthesis, cells were incubated $1.5 \mathrm{~h}$ after invasion for $30 \mathrm{~min}$ in cycloheximide $(10 \mu \mathrm{g} / \mathrm{ml})$ to inhibit protein synthesis of the host cells. Subsequently, bacterial proteins were labelled for 2 $h$ with ${ }^{35}$ S-methionine. Extracellular bacteria grown in the absence of cells in RPMI supplemented with $10 \%$ fetal calf serum, were also labelled for $2 \mathrm{~h}$ with ${ }^{35} \mathrm{~S}$-methionine.

Immunoprecipitations. For immunoprecipitations, bacteria were lysed by rapid freezing in liquid nitrogen and incubated for $30 \mathrm{~min}$ in $0.5 \mathrm{M} \mathrm{NaCl}, 10 \mathrm{mM}$ EDTA. Subsequently, Tritonbuffer was added (final concentration $2 \%$ Triton $\mathrm{X}-100,50 \mathrm{mM}$ Tris/ $\mathrm{HCl} \mathrm{pH} 8.0$ and $0.1 \%$ BSA). Suspensions were centrifuged for $10 \mathrm{~min}$ and a monoclonal antibody, 5B7 (kindly provided by $M$. Kleerebezem), that recognizes $E$. coli PhoE trimers was added to the supernatants. After overnight incubation at $4^{\circ} \mathrm{C}, 2.5 \mathrm{mg}$ of protein A-sepharose $\mathrm{CL}-4 \mathrm{~B}$ (Pharmacia, Uppsala, Sweden) was added, and the mixture was incubated at room temperature under gentle shaking. Sepharose pellets were washed three times in Triton-buffer. Samples were analaysed by SDS-PAGE and autoradiography.

DNA manipulations and gene replacement. Standard DNA manipulations were performed according to Maniatis et $a I^{32}$ Restriction enzymes and other DNA modifying enzymes were purchased from Pharmacia (Uppsala, Sweden). The S. typhimurium phoE gene was excised from pST3 ${ }^{10}$ with $\mathrm{Clal}$ and $\mathrm{Bg} / \mathrm{I}$ and subcloned into pACYC184, digested with $\mathrm{Clal}$ and $\mathrm{BamHI}$. The resulting plasmid, pRM44 (Fig. 4), contains a unique EcoRV site in the phoE gene. This EcoRV site was used for the insertion of a tetracycline resistance box. This box was isolated from pACYC184 by digestion with Xbal and Aval. Protruding ends were filled-in with the

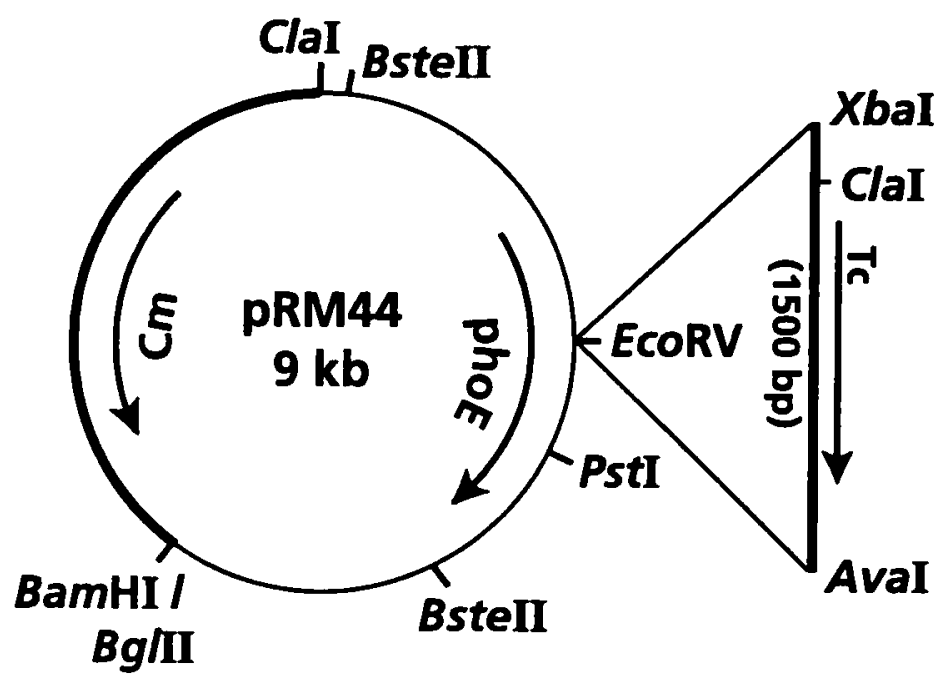

Fig. 4. Restriction map of plasmid pRM44. Fat lines represent DNA from the vector pACYC184 and the thin line chromosome-derived S. typhimurium DNA. In pRM45, a 1500 bp DNA fragment from pACYC184, containing a tetracycline-resistance marker is inserted in the EcoRV site of pRM44. The positions of the phoE gene, the chloramphenicol-resistance marker $(\mathrm{Cm})$ and the tetracycline resistance marker (Tc) are indicated by arrows. 
Klenow fragment of DNA polymerase and the tetracycline resistance box was ligated into EcoRV-digested pRM44. The resulting plasmid, pRM45, was first modified by passage through SL3261 in order to increase the electroporation efficiency. The BstEll fragment (Fig. 4 ), containing the inactivated $p h o E$ gene and the flanking DNA sequence was isolated from a low melting point agarose gel using $\beta$-agarase (New England Biolabs, Schwalbach, Germany). The linear fragment, which does not contain the origin of replication, was ligated in order to obtain circular DNA and concatemeres to improve the efficiency of homologous recombination. ${ }^{33}$ The ligated DNA was used to transform SL1344 via standard electroporation using a Biorad gene pulser, and recombinants were selected on tetracycline. Tetracycline-resistant recombinants were tested for chloramphenicol-sensitivity to identify and discard clones that contained the intact plasmid. Among the chloramphenicol-sensitive clones, correct homologous recombination was verified by Southern blotting. Chromosomal DNA was isolated ${ }^{34}$ and digested with Pst and Clal. DNA fragments were separated on a $0.6 \%$ agarose gel and transferred to nylon membranes using a vacuum blotter (Bio-Rad, Hercules, U.S.A.) according to the manufacturers' instructions. As a probe, the EcoRV-Pstl fragment of pRM44 (Fig. 4) was used. Labelling of the probe, hybridization and detection were performed with digoxigenin labelling and detection kits (BoehringerMannheim, Germany) according to the manufacturers' instructions.

Characterization of cell fractions. Protein patterns of peptidoglycan-associated proteins of recombinants were analysed on SDS-PAGE ${ }^{35}$ and Western immunoblotting. ${ }^{36}$ Peptidoglycan-associated proteins were isolated after ultrasonic disintegration of cells. ${ }^{35} \mathrm{Cell}$ envelopes were pelleted and incubated for $30 \mathrm{~min}$ at $50^{\circ} \mathrm{C}$ in a buffer containing $2 \%$ SDS. ${ }^{37}$ Peptidoglycan-associated proteins were pelleted by ultracentrifugation. A monoclonal antibody, $m E 1^{38}$ raised against $E$. coli PhoE monomers, that cross-reacts with $S$. typhimurium PhoE, was used for detection.

Infection of mice. Female Balb/c mice of 8 weeks were immunized orally with $5 \times 10^{6}$, $5 \times 10^{7}$ or $10^{9}$ bacteria in $0.5 \mathrm{ml}$ of PBS, and death rates were determined.

\section{References}

1. Mahan MJ, Slauch, JM, Mekalanos JJ. Selection of bacterial virulence genes that are specifically induced in host tissues. Science 1993; 259: 686-88.

2. Fields PI, Swanson RV, Haidaris CG, Heffron F. Mutants of Salmonella typhimurium that cannot survive within the macrophage are avirulent. Proc Natl Acad Sci USA 1986; 83: 5189-93.

3. Mekalanos JJ. Environmental signals controlling expression of virulence determinants in bacteria. $\mathrm{J}$ Bacteriol 1992; 174: 1-7.

4. Wanner BL. Gene regulation by phosphate in enteric bacteria. J Cell Biochem 1992; 51: 47-54.

5. Tommassen J, Lugtenberg B. Outer membrane protein e of Escherichia coli K-12 is co-regulated with alkaline phosphatase. J Bacteriol 1980; 143: 151-57.

6. Benz R, and Bauer K. Permeation of hydrophilic molecules through the outer membrane of Gramnegative bacteria. Eur J Biochem 1988; 176: 1-19.

7. Janssen R, Tommassen J. PhoE protein as a carrier for foreign epitopes. Int Rev Immunol 1994; 11: 113-21.

8. Orbig TG, Culp WJ, McKeehan WL, Hardesty B. The mechanism by which cycloheximide and related glutarimide antibiotics inhibit peptide synthesis on reticulocyte ribosomes. J Biol Chem 1991; 246: 174-81.

9. Bauer K, Benz R, Brass J, Boos W. Salmonella typhimurium contains an anion-selective outer membrane porin induced by phosphate starvation. J Bacteriol 1985; 161: 813-6.

10. Spierings G, Elders R, van Lith B, Hofstra H, Tommassen J. Characterization of the Salmonella typhimurium phoE gene and development of Salmonella-specific DNA probes. Gene 1992; 122: 4552.

11. Overbeeke N, Lugtenberg B. Recognition site for phosphorus-containing compounds and other negatively charged solutes on the PhoE protein pore of the outer membrane of Escherichia colik12. Eur $\mathrm{J}$ Biochem 1982; 126: 113-8.

12. Finlay BB, Falkow S. Salmonella as an intracellular parasite. Mol Microbiol 1989; 3: 1833-41.

13. Rowbury RJ, Goodson M, Wallace AD. The PhoE porin and transmission of the chemical stimulus for induction of acid resistance (acid habituation) in Escherichia coli. J Appl Bact 1992; 72: 233-43.

14. Dougan $G$, Sellwood R, Maskell $D$ et al. In vivo properties of a cloned $K 88$ adherence antigen determinant. Infect Immun 1986; 52: 344-7.

15. Brown A, Hormaeche CE, Demarco de Hormaeche $R$ et al. An attenuated aroA Salmonella typhi- 
murium vaccine elicits humoral and cellular immunity to cloned $\beta$-galactosidase in mice. $J$ Infect Dis 1987; 155: 86-92.

16. Sadoff JC, Ballou WR, Baron LS, et al. Oral Salmonella typhimurium vaccine expressing circumsporozoite protein protects against malaria. Science $1988 ; 240$ : 336-8.

17. Nakayama K, Kelley SM, Curtiss R III. Construction of an Asd" expression-cloning vector: stable maintenance and high level expression of cloned genes in a Salmonella based vaccine strain. Bio/ Technology $1988 ; 6$ : 693-7.

18. Curtiss R III, Nakayama K, Kelly SM. Recombinant avirulent Salmonella vaccine strains with stable maintenance and high level expression of cloned genes in vivo. Immunol Invest 1989; 18: 583-96.

19. Hone D, Attridge SR, van den Bosch L, Hackett J. A chromosomal integration system for stabilization of heterologous genes in Salmonella based vaccine strains. Microbial Pathog 1988; 5: 407-18.

20. Strugnell R, Maskell D, Fairweather N, et al. Stable expression of foreign antigens from the chromosome of Salmonella typhimurium vaccine strains. Gene 1990; 88: 57-63.

21. Tijhaar EJ, Yan Z-X, Karlas JA, et al. Construction and evaluation of an expression vector allowing the stable expression of foreign antigens in a Salmonella typhimurium vaccine strain. Vaccine 1994; 12: 1004-11.

22. Chatfield SN, Charles IG, Makoff AJ et al. Use of the nirB promoter to direct the stable expression of heterologous antigens in Salmonella oral vaccine strains: development of a single-dose oral tetanus vaccine. Bio/Technology 1992; 10: 888-92.

23. Agterberg M, Fransen R, Tommassen J. Expression of Escherichia coli PhoE protein in avirulent Salmonella typhimurium aroA and galE strains. FEMS Microbiol Lett. 1988; 50: 295-9.

24. Hoiseth SK, Stocker BAD. Aromatic-dependent Salmonella typhimurium are non-virulent and effective as live vaccines. Nature 1981; 291: 238-9.

25. Tommassen J, van Tol $\mathrm{H}$, Lugtenberg $B$. The ultimate localization of an outer membrane protein of Escherichia coli K-12 is not determined by the signal sequence. EMBO J 1983; 2: 1275-9.

26. Bosch D, Leunissen J, Verbakel J, de Jong $M$, van Erp H, Tommassen J. Periplasmic accumulation of truncated forms of outer-membrane PhoE protein of Escherichia coli K-12. J Mol Biol 1986; 189: 44955.

27. Chang ACY, Cohen SN. Construction and characterization of amplifiable multicopy DNA cloning vehicles derived from the p15A cryptic miniplasmid. J Bacteriol 1978; 134: 1141-59.

28. Levinthal C, Signer ER, Fetherolf $K$. Reactivation and hybridization of reduced alkaline phosphatase. Proc Natl Acad Sci USA 1962; 48: 1230-7.

29. Peters PJ, Neefjes JJ, Oorschot V, Ploegh HL, Geuze HJ. Segregation of MHC class II molecules from MHC class I molecules in the golgi complex for transport to lysosomal compartments. Nature 1991; 349: 669-76.

30. Ralph $P$, Prichard J, Cohen $M$. Reticulum cell sarcoma: an effector cell in antibody-dependent cellmediated immunity. J Immunol 1975; 143: 898-905.

31. Verjans GMGM, Ringrose JH, van Alphen L, Feltkamp TEW, Kusters JG. Entrance and survival of Salmonella typhimurium and Yersinia enterocolitica within human B- and T-cell lines. Infect Immun 1994; 62: 2229-35.

32. Maniatis T, Fritsch EF, Sambrook J. Molecular Cloning. A laboratory manual. Cold Spring Harbor Laboratory Press, Cold spring Harbor, NY 1982.

33. Yamada M, Hakura A, Sofuni T, Nohmi T. New method for gene disruption in Salmonella typhimurium: construction and characterization of an ada-deletion derivative of Salmonella typhimurium TA1535. $\mathrm{J}$ Bacteriol 1993; 175: 5539-47.

34. Marmur J. A procedure for the isolation of deoxynucleic acid from micro-organisms. J Mol Biol 1961; 3: 208-18.

35. Lugtenberg B, Meijers J, Peters R, van der Hoek P, van Alphen L. Electrophoretic resolution of the 'major outer membrane protein' of Escherichia coli K12 into four bands. FEBS Lett 1975; 58: $254-8$.

36. Agterberg M, Adriaanse H, Tijhaar E, Resink A, Tommassen J. Role of the cell surface-exposed regions of outer membrane protein PhoE of Escherichia coli $\mathrm{K} 12$ in the biogenesis of the protein. Eur. J Biochem 1989; 185: 365-70.

37. Agterberg M, Adriaanse H, Lankhof $H$, Meloen R, Tommassen J. Outer membrane protein PhoE of Escherichia coli as a carrier for foreign antigenic determinants: immunogenicity of epitopes of footand-mouth disease virus. Vaccine 1990; 8: 85-91.

38. Struyvé $M$, Visser J, Adriaanse H, Benz R, Tommassen J. Topology of the PhoE porin: the 'eyelet' region. Mol Microbiol 1993; 7: 131-40. 